\title{
Inner Retinal Layer Disease: Multiple Sclerosis
}

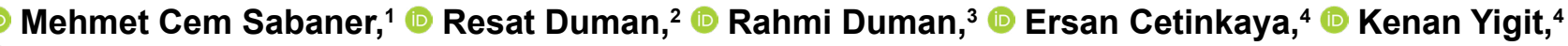 \\ Hayri Demirbas 5 \\ 1Department of Ophthalmology, Bafra State Hospital, Samsun, Turkey \\ 2Department of Ophthalmology, Bursa City Hospital, Bursa, Turkey \\ ${ }^{3}$ Department of Ophthalmology, Liv Hospital, Ankara, Turkey \\ ${ }^{4}$ Department of Ophthalmology, Sağlık Bilimleri University, Antalya Trainig and Research Hospital, Antalya, Turkey \\ ${ }^{5}$ Department of Neurology, Afyonkarahisar Health Sciences University, Faculty of Medicine, Afyon, Turkey
}

\begin{abstract}
Objectives: This study was an analysis of the retinal layer thickness in multiple sclerosis (MS) patients using spectral-domain optical coherence tomography (SD-OCT).

Methods: A total of 42 patients diagnosed in the neurology clinic with MS according to the McDonald Criteria and 21 healthy individuals were included in the study and 4 groups were created. The first group comprised 21 eyes of 21 MS patients without eye involvement, the second group was made up of 21 eyes of 21 MS patients with a history of optic neuritis, the third group included the other eye of patients in the second group without a history of optic neuritis, and the fourth group was a control group of 21 eyes of 21 healthy individuals. SD-OCT was used to visualize and measure the retinal layers and the thickness was analyzed using the device software.

Results: The mean age of the patient groups was $35.39 \pm 7.52$ years, while it was $32.86 \pm 2.60$ years in the control group. The mean duration of the disease was $9.81 \pm 6.65$ years with a mean of $4.84 \pm 2.38$ attacks. The ganglion cell layer (GCL) and the inner plexiform layer (IPL) of all of the patients were thinner compared with the control group in the parafoveal and perifoveal areas. All regions of the retinal nerve fiber layer (RNFL) of patients in the second group were thinner than those of the control group. The RNFL, GCL, and IPL in the central, parafoveal and perifoveal macular rings in group 3 were thinner than the group I measurements; however, this difference was not statistically significant. Although the RNFL, $\mathrm{GCL}$, and IPL layer thicknesses were lower in group 2 than group 3, only the difference in the parafoveal GCL thickness was statistically significant.

Conclusion: This study demonstrated that MS affects retinal layer thickness, and particularly the inner retinal layers.
\end{abstract}

Keywords: Multiple sclerosis, optical coherence tomography, optic neuritis.

\section{Introduction}

Multiple sclerosis (MS) is a chronic, autoimmune central nervous system disease characterized by demyelination and neurodegeneration. It was first described by Charcot. Although environmental and genetic factors are considered to have a significant role in the disease, the precise etiologic cause has not yet been fully understood. The prevalence range of $M S$ is
$0.002-0.2 \%$, with a geographic pattern $(I, 2)$. MS is common among young adults aged 20-30 years and the first symptoms generally occur at this age. The brain, optic nerve, and spinal cord may be affected in the earliest stages of the disease, and clinical findings reflect the affected area (3-5).The clinical process is variable. MS is classified into 4 types: relapsing-remitting, secondary progressive, progressive relapsing, and primary progressive. MS is a clinical diagnosis and there 
is no laboratory method for a definitive diagnosis. The McDonald Criteria, published by McDonald in $200 \mathrm{I}$ and revised in 2005, 2010, and 2017, are used to diagnose MS (6-9). The following changes were made in the most recent 2017 version of the McDonald Criteria: in patients with a typical clinically isolated syndrome and clinical or magnetic resonance imaging (MRI) demonstration of dissemination in space, the presence of cerebrospinal fluid-specific oligoclonal bands allows a diagnosis of multiple sclerosis; symptomatic lesions can be used to demonstrate dissemination in space or time in patients with supratentorial, infratentorial, or spinal cord syndrome; and cortical lesions can be used to demonstrate dissemination in space (9). The most common findings in MS are fatigue, weakness of I or more extremity, blurred vision, diplopia, sensorial loss, emotional changes, ataxia, and bladder dysfunction (10).

Optical coherence tomography (OCT) is a noninvasive imaging modality that differentiates tissue sections with high resolution. It was first developed in I99 I by Huang et al. (II) from the Massachusetts Institute of Technology. Technological advancements led to the ability to obtain section images with higher resolution, and it is a commonly used modality in the ophthalmology, cardiology, dermatology, and dentistry fields. In ophthalmology, OCT is used to perform a quantitative evaluation of the optic nerve, macula, and anterior segment $(12,13)$.

The primary mechanisms of damage in MS disease are demyelination and neurodegeneration. The optic nerve can be evaluated in 4 parts: the intracranial, intracanalicular, intraorbital, and intraocular components (I3). The intraocular portion is also known as the papilla or optic disc, and it is the only part of the optic nerve without myelin. Optic nerve involvement is seen in MS and it can be evaluated with OCT $(14,15)$.

The objective of this study was to analyze the thickness of the retinal layers in MS patients with or without a history of optic neuritis using spectral-domain OCT (SD-OCT) and to compare the findings with those of healthy individuals.

\section{Methods}

Forty-two patients diagnosed with MS in the neurology clinic according to the McDonald Criteria and 21 healthy volunteers were included in the study. Four groups were created. The first group included 21 MS patient without eye involvement, the second group included the eyes of 21 MS patients with a history of optic neuritis, the third group included the other eye of the patients in the second group without a history of optic neuritis, and the fourth group (control) included $2 \mathrm{I}$ eyes of $2 \mathrm{I}$ healthy individuals with similar age and gender characteristics (Fig. I). Members of the second and the third groups are the same patients.

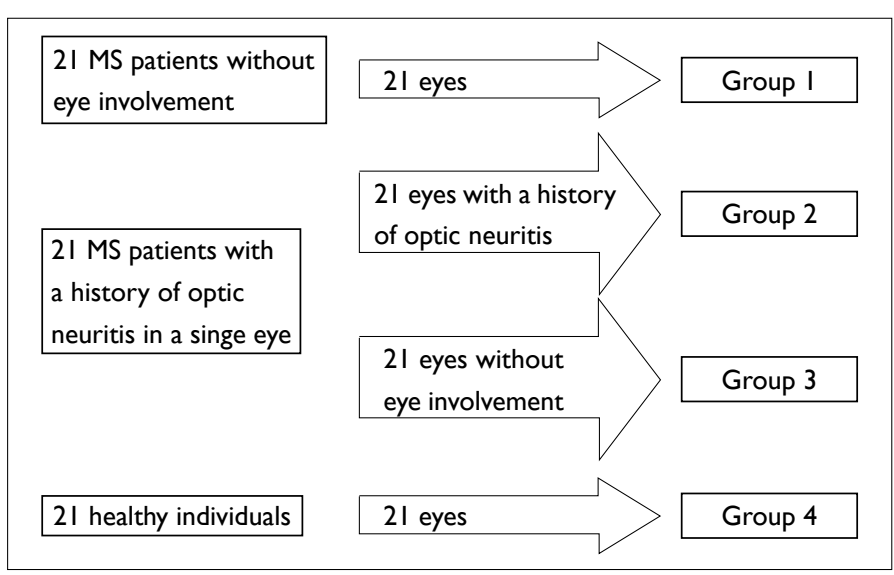

Figure I. Flow chart of the study groups.

The patients' history of optic neuritis was determined from the patient anamnesis, the hospital patient file system, and previous patient follow-up details. The inclusion criteria for all of the study individuals consisted of a spherical refraction between +1.0 and -1.0 diopters, $20 \mathrm{~mm}<$ axial length $<25 \mathrm{~mm}$, and a diagnosis of MS based on the 2017 revision of the McDonald Criteria. The following exclusion criteria were applied: the presence of ocular disease other than MS-related conditions, previous ocular surgery, a history of smoking or alcohol intake, any systemic disease, and a history of taking any medication other than MS treatment drugs within the prior 3 months.

Best-corrected visual acuity (BCVA) was measured using the Snellen chart, and the manifest refraction was measured using an automatic refractometer (RFI0; Canon Inc., Tokyo, Japan).

The SD-OCT measurements were recorded by a single experienced SD-OCT technician. The SD-OCT images were obtained in MS patients according to the APOSTEL and OSCAR-IB study recommendations $(16,17)$.

The thickness of the 7 layers described in the Early Treatment Diabetic Retinopathy Study (ETDRS) macular retina ring sectors at I, 3, and $6 \mathrm{~mm}$ was automatically analyzed with the SD-OCT device (Heidelberg Engineering $\mathrm{GmbH}$, Heidelberg, Germany) software (Segmentation Technology; Heidelberg Engineering $\mathrm{GmbH}$, Heidelberg, Germany). These are the retinal nerve fiber layer (RNFL), the ganglion cell layer (GCL), the inner plexiform layer (IPL), the inner nuclear layer (INL), the outer plexiform layer (OPL), the outer nuclear layer (ONL) and the photoreceptor-retinal pigment epithelium (RPE) complex (Figs. 2, 3).

\section{Statistical Analysis}

All of the statistical analysis was performed with IBM SPSS Statistics for Windows, Version 20.0 software (IBM Corp., Armonk, NY, USA). Generalized estimating equation (GEE) models accounting for age and adjusting for within-patient 


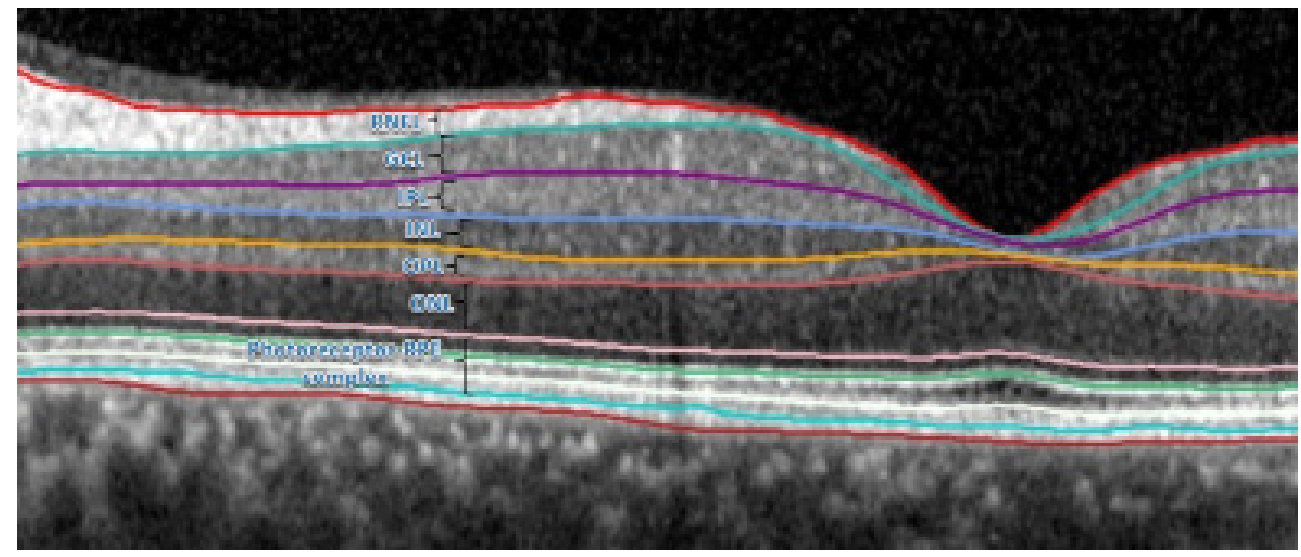

Figure 2. Image of a retinal layer analysis of a healthy eye which can be automatically analyzed with a single horizontal foveal screen using spectral-domain optical coherence tomography and the device software. GCL: Ganglion cell layer; INL: Inner nuclear layer; IPL: Inner plexiform layer: ONL: Outer nuclear layer; OPL: Outer plexiform layer; Photoreceptor-RPE: Photoreceptor retinal pigment epithelium complex; RNFL: retinal nerve fiber layer.

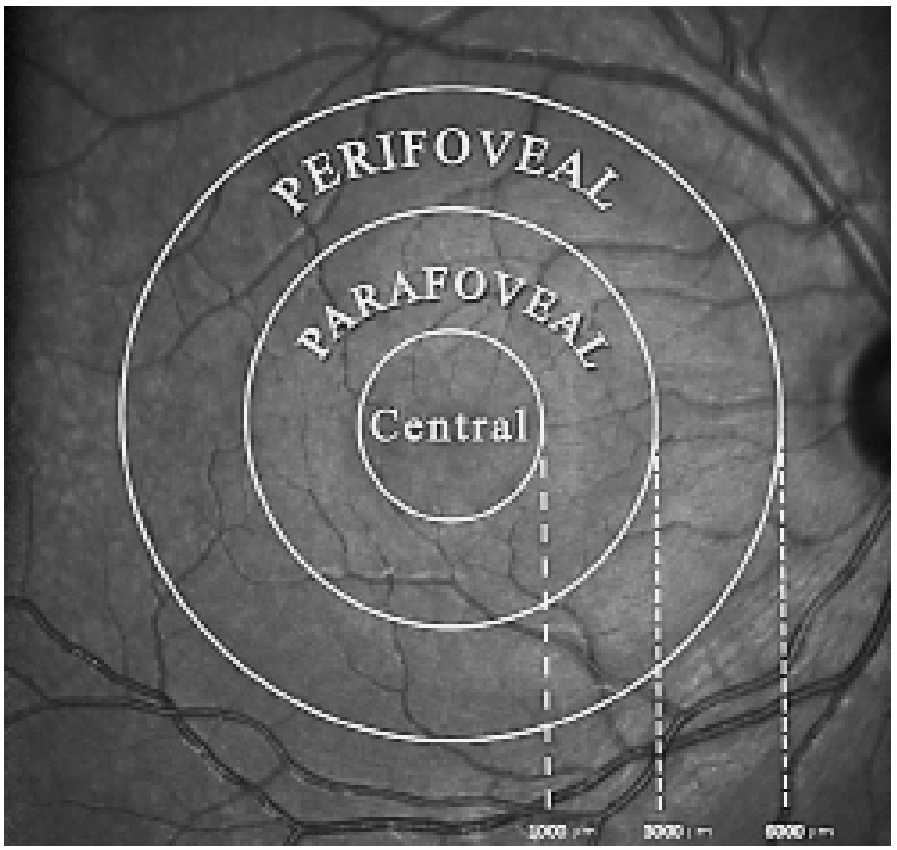

Figure 3. A demonstrative image of the Early Treatment Diabetic Retinopathy Study macular retina ring sectors at I, 3, and $6 \mathrm{~mm}$ in the central, parafoveal, and perifoveal regions.

and inter-eye correlations, were used in the analysis to determine differences in retinal layer thicknesses. The OCT results of both eyes of a single patient would be expected to have some degree of intercorrelation with respect to visual function and retinal thickness. Given that both eyes of the MS patients with a history of optic neuritis in a single eye (groups 2 and 3) were analyzed, a GEE model was created for this study to adjust for within-patient and inter-eye correlations. GEE models were also used to compare the retinal thickness values of patient and control groups. A type I error level of 0.05 was used for statistical significance (GEE mod- els, accounting for age and within-patient, inter-eye correlations). This study was an exploratory study without sample size calculation and adjustment for multiple comparisons.

This study was approved by the Istanbul Sureyyapasa Chest Diseases and Thoracic Surgery Training and Research Hospital Ethics Committee for Clinical Research (protocol code: I 16.20 17.028). All of the participants provided written informed consent and the research was conducted in accordance with the tenets of the Declaration of Helsinki.

\section{Results}

Sixty-three eyes of 42 patients ( 23 men, 19 women) with a diagnosis of relapsing-remitting MS and $2 \mathrm{I}$ eyes of $2 \mathrm{I}$ healthy volunteers (control) were included in the study (Table I). There was a history of previous optic neuritis in 21 eyes $(50 \%)$ among the MS patients. The mean duration from the onset of disease was $9.81 \pm 6.65$ years with a mean of $4.84 \pm 2.38$ attacks. The mean age was $35.01 \pm 11.97$ years in the first group, $32.26 \pm 8.53$ years in the second group, $32.26 \pm 8.53$ years in the third group, and $32.86 \pm 2.60$ years in the control group $(p=0.104, p=0.883$, and $p=0.883$, respectively) (Table I). The BCVA of the eyes in group 2 was significantly lower than that of the control group. All of the patients had been treated and followed by the neurology clinic using fingolimod, glatiramer acetate or interferon beta-la. No MS patient treated with fingolimod in this study developed macular edema.

The mean RNFL thickness value in the central, parafoveal, and perifoveal macular rings for all of the patient groups was lower than that of the control group. However, it was statistically significant only for group $2(p=0.047,0.024,0.039$, respectively) (Table 2 ).

The mean GCL thickness recorded in the central, parafove- 
Table I. Demographic details, ophthalmic findings, and disease duration in the study groups

\begin{tabular}{|c|c|c|c|c|c|}
\hline & $\begin{array}{l}\text { Group I } \\
(n=2 I)\end{array}$ & $\begin{array}{l}\text { Group } 2 \\
(n=2 I)\end{array}$ & $\begin{array}{l}\text { Group } 3 \\
(n=2 I)\end{array}$ & $\begin{array}{c}\text { Group } 4 \\
\text { (Control) }(n=2 I)\end{array}$ & $\mathbf{p}$ \\
\hline \multirow[t]{3}{*}{ Gender (male: female) } & $11: 10$ & $12: 9$ & $12: 9$ & $11: 10$ & +Group I-Control: I.000 \\
\hline & & & & & +Group2-Control: 0.758 \\
\hline & & & & & +Group3-Control: 0.758 \\
\hline \multirow[t]{3}{*}{ Age (years) } & $35.01 \pm 11.97$ & $32.26 \pm 8.53$ & $32.26 \pm 8.53$ & $32.86 \pm 2.60$ & *Group I-Control: 0.104 \\
\hline & & & & & *Group2-Control: 0.883 \\
\hline & & & & & *Group3-Control: 0.883 \\
\hline \multirow[t]{3}{*}{ BCVA (Snellen) } & $0.95 \pm 0.24$ & $0.77 \pm 0.20$ & $0.87 \pm 0.19$ & 1.0 & *Group I-Control: 0.195 \\
\hline & & & & & *Group2-Control: 0.024 \\
\hline & & & & & *Group3-Control: 0.04 I \\
\hline \multirow[t]{3}{*}{ IOP (mm-Hg) } & $14.88 \pm 2.58$ & $15.07 \pm 3.96$ & $14.72 \pm 3.20$ & $14.64 \pm 2.95$ & *Group I-Control: 0.67I \\
\hline & & & & & *Group2-Control: 0.420 \\
\hline & & & & & *Group3-Control: 0.709 \\
\hline Duration of MS disease (years) & $9.94 \pm 6.65$ & $9.48 \pm 6.75$ & $9.48 \pm 6.75$ & - & - \\
\hline
\end{tabular}

al, and perifoveal macular rings in all of the patient groups was lower than the control group result. This difference was statistically significant in the parafoveal and perifoveal rings for all of the patient groups $(p=0.041, p=0.038$ for group I; $p=<0.001$, $p<0.00$ I for group 2; $p=0.035, p=0.044$ for group 3 ).

The mean IPL thickness measurement in the central, parafoveal, and perifoveal macular rings of all of the patient groups was lower than that of the control group. This difference was statistically significant in all of the rings in group $2(p=0.036,<0.001,0.020$, respectively). It was statistically significant in the parafoveal and perifoveal macular rings in group $I$ and group $3(p=0.012, p=0.023$ for group $I$ and $p=0.040, p=0.025$ for group 3 ).

There was no statistically significant difference found in the mean thickness of the INL, OPL, ONL, RPE, or photoreceptor-RPE complex in a comparison of all of the patient groups and the control group.

The mean RNFL, GCL, and IPL thickness in the central, parafoveal, and perifoveal macular rings observed in group 3 was lower than that of group I. However, this difference was not statistically significant. Similarly, although the RNFL, $\mathrm{GCL}$, and IPL layer thicknesses were lower in group 2 than in group 3, only the difference in parafoveal $G C L$ thickness was statistically significant $(p<0.001)$.

\section{Discussion}

Although MS is known as a neurodegenerative disease with demyelination of the central nervous system, it can also in- clude eye involvement. The most form of common involvement is optic neuritis; however, peripheral retinal vasculitis, uveitis, vitreous opacities, and the involvement of the fifth, sixth, and seventh cranial nerves may be seen (18-23). Patients with optic neuritis are ordinarily examined for light reflexes in an ophthalmologic examination and relative afferent pupil defects are found in most of these patients. Optic neuritis is an acute axonal sterile inflammation affecting the optic nerve. An optic neuritis diagnosis can be made using the anamnesis, visual acuity examination, color vision, fundus examinations, contrast sensitivity, and radiologic imaging. Demyelination spots and optic nerve or periorbital nerve involvement can be identified with MRI. In the development of the OCT device, Fujimoto's use of femtosecond laser technology and Fournier's work to integrate it into the device have contributed greatly to the field of ophthalmology and neuro-ophthalmology $(24,25)$. It has been established that various temporary or permanent changes can occur in the eyes of MS patients. These changes can be rapidly and objectively identified with high repeatability and reliability by performing noninvasive imaging with OCT. The thicknesses of all of the layers in the ETDRS macular retina rings at I, 3, and $6 \mathrm{~mm}$ can be automatically analyzed with the SD-OCT software (26).

The GCL layer consists of the bodies of retinal ganglion cells. The GCL axons create the RNFL and subsequently, the optic nerve is formed. The IPL is made up of dendrites of ganglion cells which form synapses with bipolar cells as well 
Table 2. Comparison of the mean retinal layer thickness in the central, parafoveal, and perifoveal rings as measured using spectral-domain optical coherence tomography in the study groups and the control group

\begin{tabular}{|c|c|c|c|c|c|c|c|c|c|}
\hline \multirow[b]{2}{*}{ Central ( $\mu \mathrm{m})$} & \multirow[t]{2}{*}{ Group I } & \multirow[t]{2}{*}{ Group 2} & \multirow[t]{2}{*}{ Group 3} & \multirow[t]{2}{*}{ Group 4 (Control) } & \multicolumn{5}{|c|}{$\mathbf{p}^{*}$} \\
\hline & & & & & pl & p2 & p3 & p4 & p5 \\
\hline RNFL & $10.12 \pm 3.12$ & $9.64 \pm 2.13$ & $9.28 \pm 2.36$ & $11.60 \pm 2.64$ & 0.225 & 0.047 & 0.183 & 0.512 & 0.704 \\
\hline $\mathrm{GCL}$ & II.09 .3 .74 & $10.42 \pm 2.79$ & $10.86 \pm 2.73$ & $13.33 \pm 5.34$ & 0.195 & 0.089 & 0.372 & 0.733 & 0.836 \\
\hline IPL & $17.75 \pm 3.88$ & $17.00 \pm 2.00$ & $17.53 \pm 2.52$ & $20.27 \pm 4.48$ & 0.103 & 0.036 & 0.142 & 0.805 & 0.397 \\
\hline INL & $15.87 \pm 6.72$ & $|7.02 \pm 4.3|$ & $15.14 \pm 4.02$ & $16.87 \pm 5.26$ & $0.55 \mathrm{I}$ & 0.738 & 0.409 & 0.746 & 0.109 \\
\hline OPL & $23.75 \pm 7.47$ & $26.64 \pm 7.51$ & $24.57 \pm 8.28$ & $22.74 \pm 5.23$ & 0.592 & 0.163 & 0.471 & 0.607 & 0.431 \\
\hline ONL & $88.69 \pm 11.56$ & $83.50 \pm 13.29$ & $89.42 \pm 9.69$ & $90.13 \pm 10.93$ & 0.592 & 0.074 & 0.673 & 0.698 & 0.113 \\
\hline RPE & $16.18 \pm 2.24$ & $16.07 \pm 1.94$ & $|5.7| \pm 1.60$ & $15.93 \pm 1.33$ & 0.755 & 0.882 & 0.836 & 0.704 & 0.862 \\
\hline Photo-RPE & $87.31 \pm 6.22$ & $86.36 \pm 2.76$ & $86.86 \pm 3.98$ & $85.80 \pm 4.11$ & 0.490 & 0.795 & 0.708 & 0.895 & 0.805 \\
\hline \multicolumn{10}{|c|}{ Inner (parafoveal) Ring $(\mu \mathrm{m})$} \\
\hline RNFL & $20.70 \pm 3.02$ & $20.00 \pm 2.02$ & $20.21 \pm 2.33$ & $21.90 \pm 11.61$ & 0.206 & 0.024 & 0.120 & 0.719 & 0.799 \\
\hline $\mathrm{GCL}$ & $43.91 \pm 6.73$ & $38.91 \pm 7.86$ & $43.10 \pm 8.24$ & $52.73 \pm 3.51$ & 0.041 & $<0.001$ & 0.035 & 0.850 & $<0.001$ \\
\hline IPL & $37.51 \pm 4.85$ & $35.5 I \pm 4.24$ & $37.00 \pm 4.71$ & $42.33 \pm 2.91$ & 0.012 & $<0.001$ & 0.040 & 0.775 & 0.150 \\
\hline INL & $40.80 \pm 4.86$ & $40.96 \pm 4.31$ & $37.79 \pm 1.91$ & $41.03 \pm 3.07$ & 0.833 & 0.894 & 0.158 & 0.281 & 0.259 \\
\hline OPL & $33.57 \pm 4.06$ & $36.19 \pm 2.73$ & $34.64 \pm 6.19$ & $31.30 \pm 3.34$ & 0.860 & 0.106 & 0.198 & 0.700 & 0.418 \\
\hline ONL & $69.45 \pm 8.51$ & $70.04 \pm 5.63$ & $73.11 \pm 5.06$ & $71.10 \pm 6.96$ & 0.588 & 0.701 & 0.592 & 0.403 & 0.507 \\
\hline RPE & $14.62 \pm 1.32$ & $14.17 \pm 1.36$ & $13.86 \pm 1.36$ & $14.05 \pm 1.54$ & 0.316 & 0.405 & 0.927 & 0.292 & 0.310 \\
\hline Photo-RPE & $81.43 \pm 2.46$ & $80.34 \pm 1.88$ & $80.32 \pm 2.23$ & $78.44 \pm 2.05$ & 0.060 & 0.089 & 0.193 & 0.388 & 0.926 \\
\hline \multicolumn{10}{|c|}{ Outer (perifoveal) Ring $(\mu \mathrm{m})$} \\
\hline RNFL & $32.95 \pm 5.92$ & $28.87 \pm 5.14$ & $32.61 \pm 4.28$ & $35.02 \pm 3.21$ & 0.807 & 0.039 & 0.231 & 0.736 & 0.124 \\
\hline GCL & $34.35 \pm 3.05$ & $31.46 \pm 3.55$ & $34.14 \pm 4.46$ & $37.95 \pm 2.98$ & 0.038 & $<0.001$ & 0.044 & 0.484 & 0.185 \\
\hline IPL & $27.56 \pm 2.40$ & $27.26 \pm 2.66$ & $27.16 \pm 2.38$ & $30.20 \pm 2.18$ & 0.023 & 0.020 & 0.025 & 0.499 & $0.84 I$ \\
\hline INL & $34.39 \pm 2.56$ & $35.11 \pm 3.83$ & $33.21 \pm 1.51$ & $34.35 \pm 2.07$ & 0.914 & 0.671 & 0.380 & 0.125 & 0.113 \\
\hline OPL & $28.11 \pm 1.89$ & $27.91 \pm 1.80$ & $28.46 \pm 2.25$ & $27.18 \pm 1.43$ & 0.185 & 0.338 & 0.171 & 0.524 & 0.472 \\
\hline ONL & $56.30 \pm 6.88$ & $58.96 \pm 5.82$ & $59.96 \pm 5.17$ & $58.10 \pm 5.10$ & 0.431 & 0.874 & 0.662 & 0.192 & 0.723 \\
\hline RPE & $13.09 \pm 1.03$ & $|3.4| \pm 0.9 \mid$ & $12.89 \pm 1.33$ & $12.67 \pm 1.06$ & 0.287 & 0.169 & 0.650 & 0.593 & 0.369 \\
\hline Photo-RPE & $78.02 \pm 2.44$ & $77.92 \pm 1.29$ & $77.21 \pm 2.10$ & $76.38 \pm 2.31$ & 0.393 & 0.150 & $0.84 I$ & 0.509 & 0.581 \\
\hline
\end{tabular}

*: Generalized estimating equation; a type I error level of 0.05 was used for statistical significance; pI: Group I and control group, p2: Group 2 and control group, p3: Group 3 and control group, p4: Group I and Group 3, p5:p values occurred after comparison of Group 2 and Group 3. GCL: Ganglion cell layer; INL: Inner nuclear layer; IPL: Inner plexiform layer: ONL: Outer nuclear layer; OPL: Outer plexiform layer; Photo-RPE: Photoreceptor retinal pigment epithelium complex; RNFL: retinal nerve fiber layer.

as cell synapses of amacrine-bipolar-ganglion cells. The INL consists of the cell body and nuclei of bipolar cells in addition to the nuclei of amacrine cells and oval nuclei of Muller cells. Axons of rods and cones join to bipolar cell dendrites at the OPL. Fibers of horizontal and bipolar cells are also present in this layer; fibers extend at the macula area and the Henle fiber layer consists of these fibers. This layer is the most vulnerable to exudation and hemorrhage due to its position on the side of the retinal circulation $(12,13)$. The ONL consists of the nuclei of photoreceptors. The photoreceptor layer is a complicated retinal layer in which chemical reactions and electrical connections related to vision take place. The RPE is made up of a single layer of pigmented hexagonal cells between the retina and the choroid.

In our study, we found thinning of the inner retinal layers in eyes with a history of optic neuritis. We attribute this thinning to retrograde transsynaptic neurodegeneration following optic neuritis damage. Optic neuritis, which is caused by severe inflammation, is seen as retrobulbar neuritis, especially in patients with MS, and as a result, it 
has been found that it may irreversibly lead to a decrease in visual acuity and a thinning in the inner retinal layers. We also found thinning of the GCL and the IPL in the MS patient eyes without a history of optic neuritis and without eye involvement. This thinning was only seen in the paracentral and peripheral rings. It may be due to the fact that the central papillomacular bundle of RNFL may be more resistant to damage. Also, MS is a multisystemic disease and may cause subclinical damage to the optic nerve and optic nerve-associated retinal layers before causing optic neuritis.

Reduction of the thickness of retinal layers in eyes with a history of optic neuritis has been well-established (2730). Daldal et al. (3I) found that the RNFL thickness in 26 MS patients with a history of optic neuritis was substantially lower than that of MS patients without optic neuritis and a healthy control group. Garcia-Martin et al. (32) found that all of the retinal layers except the inner limiting membrane of 204 MS patients were thinner than those of healthy individuals. In a study reported by Saidha et al. (33) using the layer analysis of I46 MS patients, it was found that the $G C L+I P L, R N F L+G C L+I N L$, and INL+OPL values were lower than the equivalent values in healthy individuals. Behbehani et al. (34) found that the RNFL, GCL, IPL, and INL layer thickness of 226 eyes of II 3 MS patients was significantly lower than the control group measurement. In another study, Fernandes et al. (35) observed that the RNFL, GCL, IPL, and INL layer thickness of 262 eyes of I3I MS patients was lower than that of the control group. Buttanri et al. (36) found that the ganglion cell complex consisting of the RNFL, GCL, and IPL, of 84 MS patients was substantially thinner than those of healthy patients (Table 3). Our results were similar, which we believe can be credited to the fact that optic neuritis and eye involvement before optic neuritis are phenomena that involve ganglion cells and their extensions in retrograde transsynaptic neurodegeneration. The RNFL, GCL, and IPL layers are affected in this process (Fig. 4). In our study, the neurology clinic treated all of the MS patients with fingolimod, glatiramer acetate, or interferon beta-la drugs, which led to a low mean number of relapses $(4.84 \pm 2.38$ attacks). MS attacks include more than just those due to optic neuritis. MS has many forms of attack with various symptoms, such as numbness, weakness, inability to urinate, and gait disturbance. There was only I optic neuritis attack among patients in group 2 . We believe that the layer thinning was limited in the inner layers due to the low attack rate of the MS patients with regular follow-ups and treatment. Garcia-Martin et al. (32) reported outer layer involvement in MS, which we thought may have been due to the $34.8 \%$ of the patient group who were untreated and had recurrent optic neuritis.

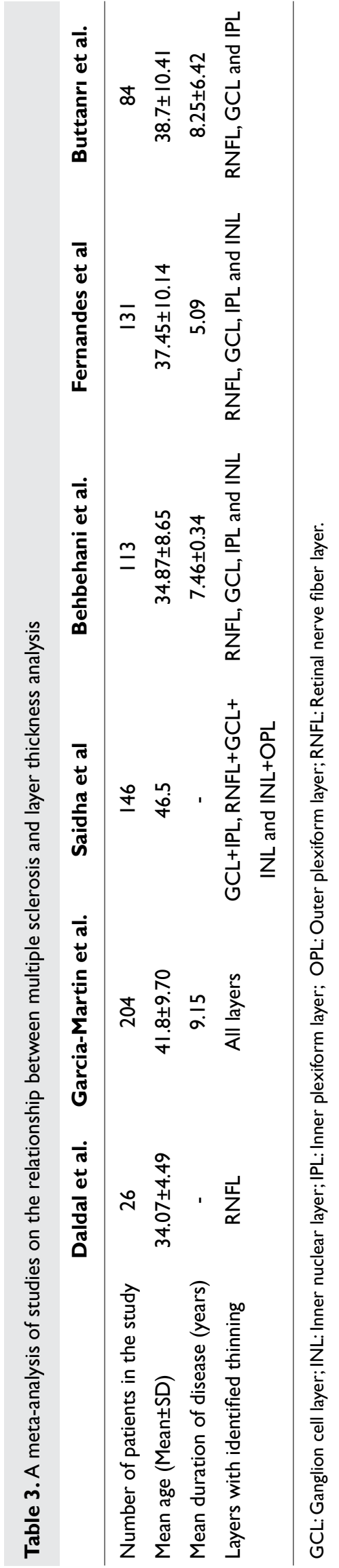



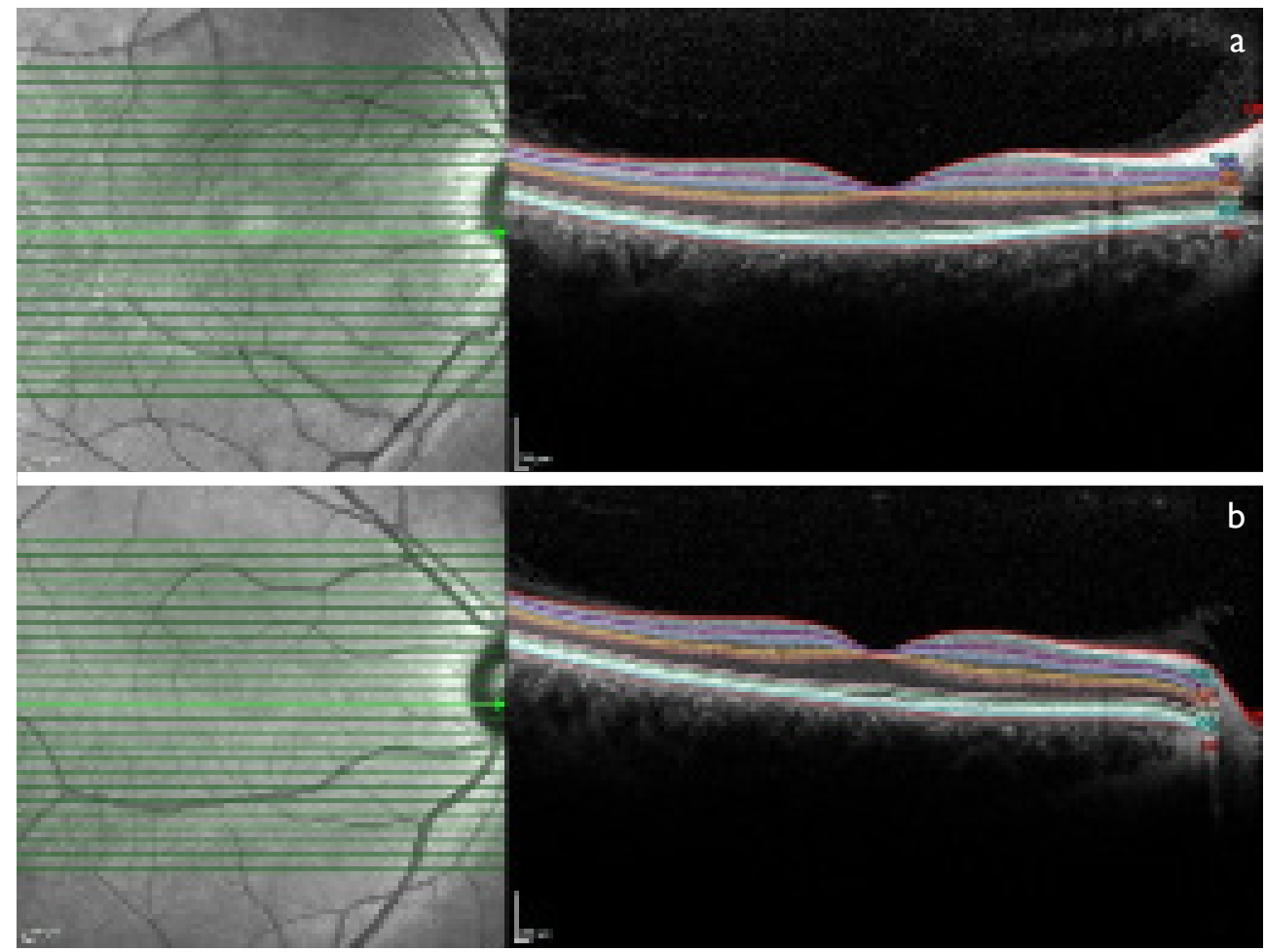

Figure 4. Differences were observed in the thickness of the retinal nerve fiber layer (RNFL), the ganglion cell layer (GCL) and the inner plexiform layer (IPL) when compared with an eye from group 4 (control group): (a) An eye with a history of optic neuritis; (b) Spectral-domain optical coherence tomography segmentation analysis.

One or more optic neuritis attacks can occur in MS patients (37-39). Furthermore, optic neuritis attacks may also be seen in the fellow eye at the same or different times $(13,39,40)$. Although there have been many clinical studies of the eyes of MS patients with the history of optic neuritis, there are only a few studies that have included the fellow eye of MS patients with a history of optic neuritis (4I). Although the RNFL, GCL, and IPL thicknesses were lower in group 3 compared with group I in our study, this result was not statistically significant. We believe that this thinning seen without optic neuritis was due to the fact that MS is a chronic multisystem neurodegenerative disease. According to these findings, patients with a history of optic neuritis should be followed up closely for both eyes.

Interestingly, the RNFL, GCL, and IPL differences between group 2 and 3 were not statistically significant in most areas. Our results indicated that although the RNFL, $\mathrm{GCL}$, and IPL layer thicknesses were lower in group 2 than in group 3, only the difference in parafoveal GCL thickness was statistically significant. The reason for this may be that optic neuritis sequelae mostly involve the GCL layer and cause damage. The lack of a statistically significant difference between groups in the fovea region was due to the absence or excessive thinness of the inner retinal layers in the fovea and adjacent fovea. It is not yet known why retinal thinning takes place in the parafoveal and perifoveal regions, especially the parafoveal region. Also, there is no completely satisfactory pathophysiological explanation of the observed selective changes in these inner retinal layers.

The main limitations of this study are the small sample size, the retrospective design, and the inclusion of only I type of MS (relapsing-remitting). We suggest that additional studies with a larger patient group with longer follow-up periods and other MS types should be performed.

In conclusion, this study demonstrated that MS affects retinal layer thickness, and the inner layers in particular. Another result of this study indicating that analysis of the ganglion cell complex of the inner retinal layers with SDOCT for early monitoring of axonal damage and neurodegeneration in MS patients may be an important tool, as we observed thinning in eyes without an optic neuritis history. These findings may be useful in further understanding the pathophysiology of MS and developing different treatment strategies. Additional studies with large case series including other subtypes of MS and long follow-up periods are needed.

\section{Disclosures}

Special thanks to public health specialist Dr. Hasan Nadir Rana for assistance with the statistical analysis section. 
Ethics Committee Approval: The study adhered to the tenets of the Declaration of Helsinki. Istanbul Sureyyapasa Chest Diseases and Thoracic Surgery Training and Research Hospital Ethics Committee of Clinical Research approved the study protocol (Protocol code: I 16.2017.028).

Peer-review: Externally peer-reviewed.

Conflict of Interest: None declared.

Authorship Contributions: Involved in design and conduct of the study (MCS, RD, RD, HD); preparation and review of the study (MCS, EC, KY, RD, RD, HD); data collection (MCS, EC, KY); and statistical analysis (MCS, EC, KY).

\section{References}

I. Krieger SC, Cook K, De Nino S, Fletcher M. The topographical model of multiple sclerosis: A dynamic visualization of disease course. Neurol Neuroimmunol Neuroinflamm 2016;3:e279.

2. Börü UT, Taşdemir M, Güler N, Ayık ED, Kumaş A, Yıldırım S, et al. Prevalence of multiple sclerosis: door-to-door survey in three rural areas of coastal Black Sea regions of Turkey. Neuroepidemiology 201 1;37:231-5. [CrossRef]

3. Azevedo CJ, Overton E, Khadka S, Buckley J, Liu S, Sampat M, et al. Early CNS neurodegeneration in radiologically isolated syndrome. Neurol Neuroimmunol Neuroinflamm 2015;2:el 02.

4. Pawlitzki M, Neumann J, Kaufmann J, Heidel J, Stadler E, Sweeney-Reed C, et al. Loss of corticospinal tract integrity in early MS disease stages. Neurol Neuroimmunol Neuroinflamm 2017;4:e399. [CrossRef]

5. Alcaide-Leon P, Cybulsky K, Sankar S, Casserly C, Leung G, Hohol M, et al. Quantitative spinal cord MRI in radiologically isolated syndrome. Neurol Neuroimmunol Neuroinflamm 2018;5:e436. [CrossRef]

6. McDonald WI, Compston A, Edan G, Goodkin D, Hartung HP, Lublin FD, et al. Recommended diagnostic criteria for multiple sclerosis: guidelines from the International Panel on the Diagnosis of Multiple Sclerosis. Ann Neurol 200 1;50:I21-7. [CrossRef]

7. Polman $\mathrm{CH}$, Reingold SC, Edan G, Filippi M, Hartung HP, Kappos L, et al. Diagnostic criteria for multiple sclerosis: 2005 revisions to the "McDonald Criteria". Ann Neurol 2005;58:840-6.

8. Polman CH, Reingold SC, Banwell B, Clanet M, Cohen JA, Filippi $M$, et al. Diagnostic criteria for multiple sclerosis: 2010 revisions to the McDonald criteria. Ann Neurol 201 I;69:292-302.

9. Thompson AJ, Banwell BL, Barkhof F, Carroll WM, Coetzee T, Comi G, et al. Diagnosis of multiple sclerosis: 2017 revisions of the McDonald criteria. Lancet Neurol 2018; 17:162-73. [CrossRef]

10. de Sa JC, Airas L, Bartholome E, Grigoriadis N, Mattle H, Oreja-Guevara C, et al. Symptomatic therapy in multiple sclerosis: a review for a multimodal approach in clinical practice. Ther Adv Neurol Disord 201 I;4:139-68. [CrossRef]

II. Huang D, Swanson EA, Lin CP, Schuman JS, Stinson WG, Chang $W$, et al. Optical coherence tomography. Science 1991;254: | |78-8|. [CrossRef]
12. Özdemir H, Arf S, Karaçorlu M. Maküla Hastalıklarında Optik Koherans Tomografi. İstanbul: Güneş Tıp Kitapevleri; 20I5. p. 3-2I.

13. Kanski J, Bowling B. Neuro-ophthalmology. In: Bowling B, editor. Clinical ophthalmology: Systematic approach. 8th ed. Elsevier; 2016. p. 774-848.

14. Oberwahrenbrock T, Traber GL, Lukas S, Gabilondo I, Nolan $\mathrm{R}$, Songster $\mathrm{C}$, et al. Multicenter reliability of semiautomatic retinal layer segmentation using OCT. Neurol Neuroimmunol Neuroinflamm 2018;5:e449. [CrossRef]

15. Petzold A, Balcer LJ, Calabresi PA, Costello F, Frohman TC, Frohman EM, et alL. Retinal layer segmentation in multiple sclerosis: a systematic review and meta-analysis. Lancet Neurol 2017; 16:797-8I2. [CrossRef]

16. Cruz-Herranz A, Balk LJ, Oberwahrenbrock T, Saidha S, Martinez-Lapiscina EH, Lagreze WA, et al. The APOSTEL recommendations for reporting quantitative optical coherence tomography studies. Neurology 2016;86:2303-9. [CrossRef]

17. Schippling S, Balk LJ, Costello F, Albrecht P, Balcer L, Calabresi PA, et al. Quality control for retinal OCT in multiple sclerosis: validation of the OSCAR-IB criteria. Mult Scler 20I5;2I:I6370. [CrossRef]

18. Brandt AU, Specovius S, Oberwahrenbrock T, Zimmermann HG, Paul F, Costello F. Frequent retinal ganglion cell damage after acute optic neuritis. Mult Scler Relat Disord 2018;22:I4I-7.

19. Soelberg K, Jarius S, Skejoe H, Engberg H, Mehlsen JJ, Nilsson $A C$, et al. A population-based prospective study of optic neuritis.Mult Scler 2017;23:1893-901. [CrossRef]

20. Galetta SL, Villoslada P, Levin N, Shindler K, Ishikawa H, Parr $E$, et al. Acute optic neuritis: Unmet clinical needs and model for new therapies. Neurol Neuroimmunol Neuroinflamm 20I5;2:el35. [CrossRef]

21. Kinyas Ş, Esgin H. Peripheral Vasculitis, Intermediate Uveitis and Interferon Use in Multiple Sclerosis. Turk J Ophthalmol 2016;46:4I-3. [CrossRef]

22. Sarıgül A, Bayar SA,Şingar E, Pınarcı EY, Oto S. A Case of Multiple Sclerosis Presented with 5th, 6th and 7th Cranial Nerve Paralysis. Turk J Ophthalmol 2015;45:8I-3. [CrossRef]

23. Petzold A, Wattjes MP, Costello F, Flores-Rivera J, Fraser CL, Fujihara $\mathrm{K}$, et al. The investigation of acute optic neuritis: a review and proposed protocol. Nat Rev Neurol 2014;10:447-58.

24. Nassif N, Cense B, Park B, Pierce M, Yun S, Bouma B, et al. In vivo high-resolution video-rate spectral-domain optical coherence tomography of the human retina and optic nerve. Opt Express 2004; 12:367-76. [CrossRef]

25. Wojtkowski M, Srinivasan V, Ko T, Fujimoto J, Kowalczyk A, Duker J. Ultrahigh-resolution, high speed, Fourier domain optical coherence tomography and methods for dispersion compensation. Opt. Express 2004; I 2:2404-22. [CrossRef]

26. Wolf-Schnurrbusch UE, Ceklic L, Brinkmann CK, Iliev ME, Frey M, Rothenbuehler SP, Enzmann V, Wolf S. Macular Thickness 
Measurements in Healthy Eyes Using Six Different Optical Coherence Tomography Instruments. Invest Ophthalmol Vis Sci 2009;50:3432-7. [CrossRef]

27. Oberwahrenbrock T, Schippling S, Ringelstein M, Kaufhold F, Zimmermann H, Keser N, et al. Retinal Damage in Multiple Sclerosis Disease Subtypes Measured by High-Resolution Optical Coherence Tomography. Mult Scler Int 2012;2012:530305.

28. Albrecht P, Ringelstein M, Müller AK, Keser N, Dietlein T, Lappas $A$, et al. Degeneration of retinal layers in multiple sclerosis subtypes quantified by optical coherence tomography. Mult Scler 2012; 18: |422-9. [CrossRef]

29. Fjeldstad AS, Carlson NG, Rose JW. Optical coherence tomography as a biomarker in multiple sclerosis. Expert Opin Med Diagn 2012;6:593-604. [CrossRef]

30. Walter SD, Ishikawa H, Galetta KM, Sakai RE, Feller DJ, Henderson SB, et al. Ganglion cell loss in relation to visual disability in multiple sclerosis. Ophthalmology 2012;1 19:1250-7. [CrossRef]

3I. Daldal H, Yalçın Ö, Şengeze N, Koyuncuoğlu HR, Tök L, Özkaya $D$, et al. Nerve Fiber Layer Thickness in Multiple Sclerosis. Turk J Ophthalmol 20I I;4I:I-5. [CrossRef]

32. Garcia-Martin E, Pueyo V, Ara JR, Almarcegui C, Martin J, Pablo $L$, et alJ. Effect of optic neuritis on progressive axonal damage in multiple sclerosis patients. Mult Scler 201 I; 17:830-7. [CrossRef]

33. Saidha S, Syc SB, Ibrahim MA, Eckstein C, Warner CV, Farrell $\mathrm{SK}$, et al. Primary retinal pathology in multiple sclerosis as detected by optical coherence tomography. Brain 20 I I; I34:5 I833. [CrossRef]
34. Behbehani R, Abu Al-Hassan A, Al-Salahat A, Sriraman D, Oakley JD, Alroughani R. Optical coherence tomography segmentation analysis in relapsing remitting versus progressive multiple sclerosis. PLoS ONE 2017; 12:e0 I72।20. [CrossRef]

35. Fernandes DB, Raza AS, Nogueira RG, Wang D, Callegaro D, Hood DC, et al. Evaluation of inner retinal layers in patients with multiple sclerosis or neuromyelitis optica using optical coherence tomography. Ophthalmology 2013;120:387-94. [CrossRef]

36. Buttanrı IB, Gencer M, Sevim S, Delipoyraz I. Evaluation of Ganglion Cell Complex Layer Thickness with Optical Coherence Tomography in Multiple Sclerosis Patients. Ret-Vit 2014;22:262-6.

37. Lennon VA, Wingerchuk DM, Kryzer TJ, Pittock SJ, Lucchinetti $\mathrm{CF}$, Fujihara $\mathrm{K}$, et al. A serum autoantibody marker of neuromyelitis optica: distinction from multiple sclerosis. Lancet 2004; 364:2106-12. [CrossRef]

38. The Optic Neuritis Study Group. Multiple Sclerosis Risk after Optic Neuritis: Final Optic Neuritis Treatment Trial Follow-Up. Arch Neurol 2008;65:727-32. [CrossRef]

39. Kale N, Optic neuritis as an early sign of multiple sclerosis. Eye Brain 2016;8:195-202. [CrossRef]

40. Chan JW. Optic neuritis in multiple sclerosis. Ocul Immunol Inflamm 2002;10:161-86. [CrossRef]

4I. Walter SD, Ishikawa H, Galetta KM, Sakai RE, Feller DJ, Henderson SB, et al. Ganglion Cell Loss in Relation to Visual Disability in Multiple Sclerosis. Ophthalmology 2012; I 19:1250-7. 